\title{
INFANCIA, GÉNERO Y MEDICINA. UN ANÁLISIS HISTÓRICO DE LOS DISCURSOS ENDOCRINOLÓGICOS SOBRE EL SÍNDROME ADIPOSO GENITAL EN BUENOS AIRES Y BARCELONA
}

\author{
Cecilia Rustoyburu \\ CONICET- Centro de Estudios Históricos (Cehis)- Universidad Nacional de Mar del Plata. \\ Email: ceciliarustoyburu@yahoo.com.ar \\ ORCID iD: http://orcid.org/0000-0002-8904-1620
}

Recibido: 12 abril 2016; Aceptado: 12 enero de 2017.

Cómo citar este artículo/Citation: Rustoyburu, Cecilia (2017), "Infancia, género y medicina. Un análisis histórico de los discursos endocrinológicos sobre el síndrome adiposo genital en Buenos Aires y Barcelona", Asclepio, 69 (1): p177. doi: http://dx.doi. org/10.3989/asclepio.2017.09

RESUMEN: Este trabajo pretende contribuir a la problematización de las lecturas sobre la obesidad y la sexualidad infantil a través de un análisis histórico de los discursos de la endocrinología en Buenos Aires y Barcelona, en las décadas de 1920 y 1930. Focalizaremos en dos escenarios de una controversia en torno de la obesidad de los varones que articuló saberes de la endocrinología con supuestos morales sobre las familias y representaciones de género. Nuestro objetivo es identificar cómo se resignificaron los saberes sobre hormonas sexuadas disponibles en el campo científico internacional, en el marco de las experiencias clínicas locales. Consideramos que los endocrinólogos se valieron de estereotipos de género para leer los cuerpos de sus pacientes, pero sus interpretaciones también estuvieron mediadas por los intereses y las lógicas de las instituciones de las que formaron parte. La relevancia del psicoanálisis en Buenos Aires y la importancia de la tradición experimental en Barcelona serán aspectos centrales para identificar las particularidades de cada caso. Nuestro corpus documental está constituido por publicaciones científicas especializadas.

PALABRAS CLAVE: Endocrinología; Infancia; Obesidad; Género; Sexualidad.

\section{CHILDHOOD, GENDER AND MEDICINE. A HISTORICAL ANALYSIS OF ENDOCRINOLOGICAL DISCOURSES ON GENITAL ADIPOSE SYNDROME IN BUENOS AIRES AND BARCELONA}

ABSTRACT: This paper aims to contribute to the problematization of the interpretation on obesity and childhood sexuality through a historical analysis of the speeches of endocrinology in Buenos Aires and Barcelona in the 1920s and 1930. We will focus on two stages of a controversy around obesity of boy who articulated knowledge of endocrinology with moral assumptions about families and gender representations. Our goal is to identify how knowledge about sexed hormones available in the international scientific field, in the context of local clinical experiences resignified. Endocrinologists believe that availed themselves of gender stereotypes to read the bodies of their patients, but their performances were also mediated by the interests and the logic of the institutions of which they were part. The relevance of psychoanalysis in Buenos Aires and the importance of the experimental tradition in Barcelona will be central aspects to identify the particularities of each case. Our documentary corpus consists of specialized scientific publications.

KEY WORDS: Endocrinology; Childhood; Obesity; Gender; Sexuality.

Copyright: (C) 2017 CSIC. Este es un artículo de acceso abierto distribuido bajo los términos de la licencia Creative Commons Attribution (CC BY) España 3.0. 


\section{INTRODUCCIÓN}

La psiquiatría y el psicoanálisis no han sido las únicas disciplinas involucradas en la construcción de una scientia sexualis (Foucault, 1976). Desde el XIX, el discurso médico occidental legitimó una lectura binaria de los cuerpos sexuados (Laqueur, 1990). Los estudios de género han alertado sobre la relación entre la interpretación científica de la química corporal y la construcción social de ciertas representaciones de género (Oudshoorn, 1994; Fausto Sterling, 2006; Preciado, 2008; Glick, 2005; Huertas y Novella, 2013; Castejón, 2013; Cleminson y Vázquez, 2009). Desde la perspectiva de Fausto Sterling, las hormonas esteroides podrían haberse interpretado como hormonas de crecimiento que afectaban a órganos de todo el cuerpo. Sin embargo, entre 1900 y 1940, se convirtieron en marcadores de la diferencia sexual porque fueron leídas como sexuadas y en los términos de las luchas y disputas entre los sexos que transcurrían en las sociedades de los científicos que las estudiaron.

Hacia la segunda década del siglo XX, la endocrinología se configuró como una especialidad médica (Glick, 1976). Las enfermedades vinculadas a la química corporal se convirtieron en síndromes que muchas veces fueron leídos como relacionados con patologías psiquiátricas y psicológicas. La obesidad fue una de ellas, el exceso de peso dejó de ser interpretado como un problema estético para convertirse en una cuestión médica (Vigarello, 1995; Schencman, 2010). En este contexto, se transformaron las nociones que asimilaban la robustez de los lactantes y los niños con la buena salud en las campañas por la lactancia materna. La problematización de la obesidad infantil se tornó visible en la década de 1930, cuando los desvelos por las muertes fueron cediendo espacio a las preocupaciones por la baja en los nacimientos.

En los discursos condenatorios de la obesidad habrían jugado un rol importante tanto la moral occidental cristiana que reclamaba mesura y menospreciaba la gula, como la evolución del conocimiento científico que mostró la vinculación entre salud y dieta, y los cambios en las representaciones del cuerpo que convirtieron a la delgadez en un signo de salud, disciplina y control social (Gracia-Arnaiz (ed), 2012). En Argentina, la obesidad infantil también se visibilizó como un indicador de ciertos excesos y como un desequilibrio de salud no sólo físico sino también psíquico. Los diagnósticos estuvieron relacionados con las preocupaciones por la desnatalidad y la resignificación de algunos discursos del psicoanálisis.
En Buenos Aires, la supuesta adiposidad de los varones se asoció a su carácter de hijos únicos. La endocrinología y el psicoanálisis conformaron una matriz discursiva que interpretó a esos niños como casos de síndrome adiposo genital, y leyó a esta patología como de origen familiar-ambiental, relacionada con la sobreprotección materna o con la insatisfacción sexual de la madre y/o el padre.

En el campo médico internacional, la denominación síndrome adiposo genital solía utilizarse como una definición rutinaria ante los niños gordos y para referirse al Síndrome de Fröhlich, una patología que combinaba obesidad con atrofia genital y que se entendía que era producto de un desequilibrio hormonal. ${ }^{1}$ En la primera mitad del siglo XX, sus causas y sus tratamientos conformaron una controversia científica (Collins, [1975] 1995) que incluía a expertos europeos, norteamericanos y latinoamericanos. Se debatía la importancia relativa de la pineal, las gónadas, la hipófisis y el hipotálamo; y la efectividad de las distintas estrategias de curación. Las explicaciones fisiológicas no eran ajenas a los sesgos de género, especialmente en las descripciones anatómicas y psicológicas de los pacientes. La adiposidad en las caderas o en las mamas y el carácter místico o fantasioso fueron interpretados como signos de feminidad. En España, estas interpretaciones y debates adquirieron resonancia. Dicho síndrome fue adjudicado a niños y niñas en los consultorios de endocrinología, en los laboratorios de fisiología y en los dictámenes psico-pedagógicos. En la década de 1920, un endocrinólogo de Barcelona logró repercusión internacional porque publicó una serie de casos que habrían sido curados mediante la aplicación de rayos $X$ en la hipófisis.

Este trabajo pretende contribuir a la problematización de las lecturas sobre la obesidad y la sexualidad infantil a través de un análisis histórico de los discursos de la endocrinología en Buenos Aires y Barcelona, en las décadas de 1920 y 1930 . Focalizaremos en dos escenarios de una controversia en torno de la obesidad de los varones que articuló saberes de la endocrinología con supuestos morales sobre las familias y representaciones de género. Nuestro objetivo es identificar cómo se resignificaron los saberes sobre hormonas sexuadas disponibles en el campo científico internacional, en el marco de las experiencias clínicas locales. Consideramos que los endocrinólogos se valieron de estereotipos de género para leer los cuerpos de sus pacientes, pero sus interpretaciones también estuvieron mediadas por los intereses y las lógicas de las instituciones de las que formaron parte. 
Profundizaremos en los diagnósticos y los tratamientos implementados en el consultorio de psico-neuroendocrinología del Hospital de Niños de la ciudad de Buenos Aires y en el Dispensario de Endocrinología de la Cátedra de Terapéutica de la Facultad de Medicina de Barcelona. El espacio argentino adquirió relevancia por el prestigio internacional del Servicio en el que funcionaba y porque los médicos que allí se desempeñaron fueron fundadores de la Sociedad Argentina de Endocrinología y Metabolismo y de la Asociación Psicoanalítica Argentina. En el consultorio de Barcelona atendían los principales referentes de la escuela catalana de endocrinología que integraron la Societat de Biología y el Laboratorio de Fisiología del Institut d’Estudis Catalans. Nuestro corpus documental está constituido por publicaciones científicas especializadas.

\section{ENTRE CONSULTORIOS Y LABORATORIOS}

En Argentina, la circulación de las ideas científicas sobre hormonas fue temprana. Desde principios del siglo XX, algunas revistas como Vox Médica y La Semana Médica publicaron traducciones de los experimentos de investigadores europeos y proliferaron anuncios que comercializaban extractos de glándulas. Desde fines del siglo XIX, los médicos de ese país estudiaron en el extranjero y formaron parte de laboratorios reconocidos de Europa y Estados Unidos. En las primeras décadas del siglo $X X$, se crearon institutos de fisiología en las ciudades de Buenos Aires, Córdoba y Rosario (Buch, 2006). En este desarrollo tuvo una importancia fundamental el financiamiento de la Fundación Rockefeller. Los fisiólogos desarrollaron estudios sobre el ciclo sexual femenino, hormonas y hormonoterapia, con el apoyo de la Fundación y en relación con endocrinólogos constitucionalistas norteamericanos (Eraso, 2007). Algunos científicos argentinos alcanzaron prestigio mundial. Bernardo Houssay fue galardonado con el premio Nobel por sus investigaciones sobre la hipófisis y el páncreas; Roberto Pascualini y a Grato Bur alcanzaron amplia resonancia por sus intervenciones clínicas en eunucoidismo; y las investigaciones de Carlos Galli Mainini sobre la gonadotropina coriónica resultaron fundamentales para la elaboración de test de embarazo (Cepeda, 2011). Desde 1933, la endocrinología también encontró un espacio relevante en la Asociación Argentina de Biotipología, Eugenesia y Medicina Social ligada a la Escuela de Biotipología fundada en Italia por Nicola Pende (Rustoyburu, 2012a). En la década de 1930, la hormonoterapia era una técnica difundida entre los ginecólogos tanto para atender correcciones genitales como disfunciones menstruales y problemas de esterilidad
(Eraso, 2007). En el Hospital de Niños, los endocrinólogos se vincularon al psicoanálisis y formaron parte de la introducción de la medicina psicosomática.

En España, la endocrinología también alcanzó un desarrollo temprano a partir de la discusión de los trabajos de Claude Bernard y Carl Brown-Sèquard. Desde la segunda década del siglo XX, se puede hablar de un movimiento endocrinológico español con la consolidación de las escuelas catalana y madrileña (Glick, 1976; Orozco Acuaviva, 1999). La primera publicación, Archivos de Endocrinología y Nutrición, fue fundada en 1924 por Gregorio Marañón. La presidió junto al catalán Augusto Pi i Suñer y el argentino Bernardo Houssay, hasta 1927 cuando dejó de editarse. En esa publicación puede apreciarse el amplio abanico de patologías que atendían y la difusión de los opoterápicos. En sus páginas, no predominaron las enfermedades referidas a los órganos reproductivos y genitales. Sin embargo, se visualiza un debate con "los feministas" donde los endocrinólogos reafirmaban la determinación biológica del rol de la mujer. Esto no era ajeno al devenir histórico. En este país, la mirada médica decimonómica contribuyó a la sexualización de los cuerpos construida por la ciencia occidental. Así la feminidad fue pensada como opuesta a la inteligencia, y la instrucción era entendida como incompatible con la procreación. Marañón afirmaba que la función natural y social de la mujer "normal" era la reproducción y el ejercicio de la maternidad, aunque admitiera su probada capacidad para ejercer otras actividades. Este posicionamiento lo acercaba a las feministas que fundamentaban sus reivindicaciones sociales y políticas desde el maternalismo (Aresti, 2001; Castejón, 2013). Las lecturas que hacían hincapié en la inferioridad fueron perdiendo preminencia, en la década de 1930 , ante ciertas perspectivas que visibilizaban la diversidad de mujeres. Esto era compatible con la nueva situación social y económica en la que éstas tenían mayor presencia en el ámbito público, y daba cuenta de los diálogos que algunos sectores de la medicina entablaron con las feministas más importantes de los años veinte (Ortiz Gómez, 1993; Aresti, 2001).

En Cataluña, desde fines del siglo XIX, Ramón Turró i Darder se destacó por sus trabajos sobre la medicación tiroidea, la obesidad y la pancreatina. En los inicios del siglo XX, Pi i Suñer adquirió reconocimiento por sus estudios sobre la función fijadora del hígado y la glucopatía, y por su concepción holística de las correlaciones químicas. A partir de 1912, un grupo de biólogos que se dedicaban a la endocrinología experimental se agruparon en la Societat Catalana de 
Biología del Institut d’Estudis Catalans. Ese grupo estaba conformado por Pi i Suñer, Turró i Darder, Jesús María Bellido y Leandre Cervera i Astor, los principales exponentes de la escuela catalana. En 1917, ese espacio adquirió visibilidad porque fue el escenario de la presentación de las Cuatro lecciones sobre secreciones internas de Eugène Gley, una obra que se convirtió en una referencia para los especialistas (Orozco Acuaviva, 1999).

Estos entramados institucionales son elementos indispensables para comprender el proceso de construcción de los discursos en torno del síndrome adiposo genital. En Buenos Aires, la endocrinología dialogó con la psicología, la psiquiatría y el psicoanálisis. En el Hospital de Niños, los pacientes leídos como obesos fueron derivados a una sala en la que se desempeñaban médicos que formaron parte de la fundación de las primeras instituciones colegiadas de esas especialidades. En Barcelona, el dispensario de la Cátedra de la Facultad de Medicina estaba conformado por biólogos experimentales y médicos. Su perspectiva los acercó al grupo de endocrinólogos argentinos vinculados a la fisiología. En 1919, Pi i Suñer y Cervera i Astor visitaron Argentina, participaron de las contiendas locales a favor de Houssay e iniciaron un período de intercambios de experiencias y de alianzas entre ambos laboratorios que se alineaban a la perspectiva crítica de Gley (Buch, 2006). ${ }^{2}$. Esto significaba un posicionamiento cauteloso sobre los resultados de la opoterapia, y especialmente sobre el supuesto que entendía que de cualquier órgano podía extraerse una sustancia específica.

En el Hospital de Niños de Buenos Aires, parecía predominar una corriente en que el sistema nervioso tenía un papel fundamental. En 1932, cuando Rodolfo Rivarola asumió la dirección del Hospital colocó bajo una sola jefatura a las disciplinas neurológicas, psiquiátricas y endocrinológicas. El jefe de ese servicio fue el prestigioso neuropsiquiatra infantil Aguiles Gareiso, que se mantuvo en su cargo hasta 1943. Este espacio ocupó un lugar importante para los inicios de la pediatría psicosomática porque allí se llevaron a cabo los primeros diagnósticos de enfermedades somáticas desde supuestos psicoanalíticos. En este servicio, Arnaldo Rascovsky, Samuel Schere, Enrique Pichon Riviere, Juan Carlos Perellano, Jaime Salzman, Teodoro Sholossberg y Gregorio Ferrari Hardoy ${ }^{3}$ resignificaron el lugar otorgado a la química hormonal en la configuración de ciertas enfermedades. Desde fines de la década de 1930, se acercaron a los textos de Sigmund Freud y emprendieron el camino para la fundación de la Asociación Psicoanalítica Argentina (APA) en 1942 (Plotkin, 2003; Dagfal, 2009; Barone, 2009; Carpintero y Vainer, 2004). Esas lecturas incidieron en sus interpretaciones sobre el origen psíquico de algunas enfermedades como la obesidad o la epilepsia. Rascovsky ha sido reconocido como uno de los primeros en realizar este tipo de estudios, uniendo sus saberes adquiridos en el laboratorio de Houssay a sus primeras aproximaciones al psicoanálisis. Las investigaciones y los análisis de casos realizados por ellos fueron presentados en las Sesiones Científicas de la Sociedad Argentina de Pediatría (SAP) y luego publicados en los Archivos Argentinos de Pediatría, su órgano oficial.

En Barcelona, el síndrome adiposo genital habría sido identificado en forma recurrente en los consultorios de endocrinología, pero estos no eran atendidos por pediatras ni funcionaban en hospitales de niños. Fue objeto de experimentación e intervención del médico y veterinario Leandre Cervera i Astor (1891-1964), un investigador de la Escola Superior d'Agricultura de la Mancomunitat de Catalunya, del Laboratori Municipal junto a Turró i Darder y del Institut de Fisiología de la Universidad de Barcelona, bajo la dirección de Pi i Suñer y Jesús María Bellido. Durante los primeros quince años de su trayectoria se dedicó a los estudios de laboratorio, pero en 1927 se convirtió en un especialista en Sindrome de Frölich por sus prácticas clínicas exitosas con rayos $\mathrm{X}$. Sus presentaciones de casos fueron publicadas y citadas en revistas científicas catalanas, francesas, alemanas y cubanas. ${ }^{4}$ En 1929, visitó Argentina acompañando a Pi i Suñer y formó parte de un curso organizado por el Instituto de Fisiología donde también intervinieron De Quervain, Marañón, Pittaluga, Jiménez Díaz, Carrasco Formiguera, Goyanes, Bellido y Carulla. En 1933, ingresó a la Academia de Ciencias Médicas de Barcelona. En ese acto pronunció su discurso "De l'Opoteràpia a I'Hormonoteràpia. Endocrinología 1917-1933", donde reivindicó el aporte de Gley. En ese mismo año, publicó "La pubertad normal" y "La pubertad patológica" en Monografies Mèdiques. Fue secretario y presidente de la Societat de Biología, y fundador y editor de la revista La Medicina Catalana. En sus presentaciones, las explicaciones de las causas del síndrome y de su tratamiento las fundaba en el funcionamiento glandular. Sin embargo, en 1934 mencionó la utilización de test psicológicos y de feminidad. Esta situación no era ajena a su vinculación con pedagogos y maestros en los Ateneos y en los Estudis Universitaris per a obrers durante la República. 
En España, los tiempos de la Guerra Civil interrumpieron las trayectorias de muchos endocrinólogos y el proceso de institucionalización iniciado en la República (Aguirre Marco, 2013; Orosco Acuavia, 1999). En Argentina, fue a partir de 1946 cuando los médicos vinculados a la APA y a la Sala XVII del Hospital de Niños tuvieron que renunciar a sus cargos en forma de protesta ante las intervenciones del gobierno peronista (Rustoyburu, 2012b; Hurtado y Fernández, 2013). Sin embargo, esto no impidió que continuaran con sus carreras académicas en los cuerpos colegiados, publicando sus investigaciones y casos clínicos en revistas especializadas nacionales e internacionales.

\section{EL SÍNDROME ADIPOSO GENITAL EN BUENOS AIRES: HIJOS ÚNICOS Y PSICOPATÍAS}

El consultorio externo de psico-neuro-endocrinología del Hospital de Niños de Buenos Aires era dirigido por Alejandro Petre. Su organización y funcionamiento pretendía replicar las experiencias desarrolladas por William Healy ${ }^{5}$ en Estados Unidos y por Édouard Pichon $^{6}$ en Francia, quienes habían creado servicios de neuropsiquiatría. En este caso, agregaron la endocrinología porque se inscribían en la tradición que consideraba que existía una influencia de los factores psicológicos en la presentación de las enfermedades hormonales. Esto suponía que las aproximaciones y las intervenciones sobre los cuerpos de las y los pacientes abarcaban múltiples dimensiones. Lo que conceptualizaban como normalidad evolutiva era medida en relación a tres niveles: afectiva, intelectual y somática. Por esto, cuando los médicos de este servicio presentaban las características de los diagnósticos, afirmaban que realizaban un estudio que incluía diferentes exámenes: psicológico y ambiental, neuropsiquiátrico, endocrinológico, foniátrico y dento-maxilo-facial, y clínicosomático. La figura del médico era central para la administración de esta serie de métodos. ${ }^{7}$

En esos años, se ejercía una "psicología sin psicólogos" porque aún no se habían formado especialistas en Argentina (Vezzetti, 1996). ${ }^{8}$ En el consultorio de psico-neuro-endocrinología, los métodos y las técnicas elaborados por psicólogos ocupaban un lugar destacado en el momento del diagnóstico y del tratamiento, que en algunos casos incluía psicoterapia. A pesar de la existencia de asistentes sociales, el análisis ambiental y psicológico se elaboraba a partir de un cuestionario destinado a los padres que era realizado por el pediatra. En estos informes, adquirían especial importancia las relaciones afectivas de la madre hacia el niño o la niña, los vínculos de la pareja y la práctica de colecho y cohabitación. Luego se sometía al niño o la niña al mismo procedimiento, aunque los test de Rorschach y Binet-Simon-Stanford, el cuestionario de Ballard, los baby-test de Buhler, la prueba de Bieuler y Jung eran aplicados por un técnico especializado. Gregorio Ferrari Hardoy, un médico foniatra formado en la escuela vienesa de Froeschels, ocupaba un lugar de relevancia en el servicio porque partían del supuesto de que el carácter y las perturbaciones de la voz - como el ceceo o el balbuceo - eran indicadores claros de la presencia de enfermedades psicoendocrinológicas. El examen neuropsiquiátrico también era realizado por los médicos, quienes solían hacer encefalografías y otras pruebas complejas que en esos tiempos requerían la internación del o la paciente.

Los aspectos endocrinológicos eran evaluados a partir de radiografías, exámenes químicos, mediciones odontológicas y especialmente fotografías. En las presentaciones de los casos y en la elaboración de los diagnósticos, las imágenes adquirían una importante presencia como pruebas válidas de las malformaciones, e inclusive de las predisposiciones anímicas. En algunas historias clínicas presentadas como ejemplos de obesidad monstruosa en lactantes, las fotos eran las únicas evidencias de que esa patología existía porque la batería de estudios realizados no les permitía probar su etiología, ni otros signos. En las narraciones de los procesos psicopatológicos, los rostros apenados y el cabello desarreglado ilustraban los ingresos de las y los niños al Servicio, y las sonrisas enmarcadas de grandes moños o gominas eran las evidencias de la curación.

Por último, se efectuaba el examen clínicosomático al que se le agregaban los informes de laboratorio, radiológicos y de metabolismo basal que se solicitaban a los distintos servicios del hospital. Luego, se elaboraba un diagnóstico que consideraba los factores ambientales, neuropsicopáticos y clínicosomáticos. Los tratamientos podían incluir psicoterapias, aislamiento de la familia, electroshock, baños de inmersión, dietas, vitaminas y hormonoterapia.

Como sucedía desde los inicios de la endocrinología, la tiroxina y la foliculina eran aplicadas en múltiples situaciones. En esa sala, Florencio Escardó trataba las vaginitis infantiles mediante la administración de estrógenos que alteraban la anatomía genital de las niñas hasta otorgarle una apariencia similar a la de las adultas. ${ }^{9}$ De esta manera, contenía las infecciones y no implementaba tratamientos invasivos que requerían manipulaciones molestas (Rustoyburu, 2012b). En este tipo de experimentos, la química corporal era estrictamente controlada por el médico y no altera- 
ba el sexo de las pacientes. En cambio, cuando los cuerpos parecían transgredir la diferencia sexual se convertían en casos de estudio, clasificación e intervención quirúrgica. Los varones que presentaban un desarrollo mamario notorio eran leídos como ginecomastas, sometidos a múltiples test y se les extirpaban las mamas aunque se tuviera en cuenta que su psiquismo era "feminoide". La aparición de esos signos sexuales secundarios era interpretada como producto de un incorrecto funcionamiento testicular, entendían que una ectopia podía ser la causa de que sus gónadas no actuaran inhibiendo a las hormonas del sexo opuesto (Rustoyburu, 2012a). Estos supuestos sobre la relación entre las hormonas y la sexualidad también actuaban como lentes desde los cuales interpretaban los cuerpos leídos como obesos. Sin embargo, en ellos la sexualidad y la química corporal eran entendidas como determinados por el ambiente familiar.

Hacia fines de la década de 1930 y a principios de la de 1940, Rascovsky, Schere, Pichon Riviere, Perellano, Salzman, Sholossberg y Ferrari Hardoy realizaron una serie de presentaciones en la SAP sobre síndrome adiposo genital. Expusieron historias clínicas de varones, atendidos en su consultorio y en la sala dirigida por Del Castillo, donde identificaban que las causas de dicho síndrome provenían del ambiente. Argumentaron que cuando las madres y los padres no mantenían relaciones armónicas y satisfactorias podían afectar el desarrollo sexual de sus hijos. Entendían que cuando el niño era hijo único, u ocupaba un lugar especial en la familia, la madre solía orientar su libido hacia él. Creían que el colecho y la cohabitación podían generar estímulos sexuales inadecuados que fijaban su desarrollo psíquico en la etapa oral, lo cual devenía en un aumento de su ansiedad que era saciada mediante la alimentación.

Esas lecturas sobre el síndrome adiposo genital se distinguían de lo planteado por los médicos de otros países que entendían que era causado por desequilibrios hormonales, y que no era una patología frecuente. En el consultorio de psico-neuro-endocrinología planteaban que la mayoría de los varones obesos padecía ese síndrome, porque la definición de obesidad a la que adscribían permitía que niños "bien proporcionados" también pudieran leerse como adiposos. Su categorización entendía que los síntomas trascendían la distribución de la grasa corporal, también suponían que los órganos sexuales podían estar afectados. En el diagnóstico, los genitales, el vello corporal y los indicadores de masculinidad del test de FeminidadMasculinidad eran aspectos tan importantes como la evaluación de las radiografías de la silla turca donde se aloja la hipófisis. En sus prácticas, al inicio y al final de los tratamientos, parecían ponerse en juego la construcción de la pubertad y de la diferencia sexual.

Esta interpretación sobre el síndrome adiposo genital formaba parte de un clima de ideas donde la obesidad comenzaba a ser interpretada como patología. En la década de 1930, en las Sesiones Científicas de la SAP, algunos lactantes obesos fueron exhibidos como monstruos. En esas presentaciones, los pediatras explicitaban que se trataba de procesos que no habían sabido modificar y de los que desconocían sus causas. Aunque, al describir las historias clínicas, mencionaban que las madres los sobrealimentaban. La no adecuación de las madres al estricto método horario de los puericultores de la época era destacada como la única posibilidad para elaborar una etiología. El aporte de estas exposiciones no radicaba en su valor científico sino en su rareza, se apelaba a su excepcionalidad por deseo de integración (Didi-Huberman, 2007).

Los casos leídos como obesidad monstruosa en lactantes eran poco frecuentes, y probablemente no eran novedosos. Sin embargo, parecían ser los casos extremos de una matriz discursiva en la que los niños obesos también podían ser "bien proporcionados". Esto se tornaba evidente en que a pesar de las preocupaciones de la época (Agüero, Milanino, Sánchez y Kohn Loncarica, 2011; Agüero, Milanino, Bortz y Isolabella, 2012), la presentación de las historias clínicas en las revistas científicas no incorporaba precisiones de talla y peso. Además, apelaban a conceptualizaciones bastante vagas de la patología. Alfredo Larguía (1938) reseñó un artículo de Nathan Talbot publicado en American Journal Disease of Children sobre la determinación de la obesidad por el coeficiente cretinúrico. Planteaba que el autor definía a la obesidad como "la acumulación de grasa subcutánea excesiva en relación a la masa muscular..." ${ }^{10}$ y agregaba que era encontrada no sólo en pacientes con peso exagerado. En las intervenciones sobre estas temáticas en Archivos Argentinos de Pediatría solían reproducirse los conceptos de Hilde Bruch ${ }^{11}$. En su conceptualización, Bruch distinguía al niño obeso del sano, y vinculaba esta patología con un problema en la evolución del esqueleto, de los órganos y de la sexualidad. A partir del estudio de ciento dos casos, afirmaba que las causas solían estar más relacionadas con la nutrición abundante que con el hipotiroidismo o el hipopituitarismo. Sin embargo, los especialistas argentinos se hicieron eco de los expertos que recomendaban los tratamientos con tiroxina, aunque el origen de la dolencia no fuera necesariamente hormonal. 
En la sesión de Pediatría del $V^{\circ}$ Congreso Nacional de Medicina, realizado en la ciudad de Rosario en 1934, Schere y Pellerano presentaron una ponencia sobre "la obesidad en la infancia" donde expusieron los resultados obtenidos del estudio de veintiún casos. Allí desarrollaron las siguientes conclusiones:

" $1^{\circ}$ La obesidad infantil debe tratarse, sobre todo la del período prepuberal, ya que, siguiendo el concepto de Laffitte y Carrié "La pubertad es para el obeso un caso peligroso; si en ese período enflaquece, la partida está ganada, si por el contrario engruesa, la pubertad se establece mal y entonces la obesidad es casi siempre irremediable."

$2^{\circ}$ La restricción alimenticia, tan útil en el tratamiento del obeso adulto, deja de serlo en el niño, siguiendo principios elementales de dietética infantil y máxime, cuando en los hipofisiarios, los cuales constituyen el mayor número de niños obesos puede, según Raab, acarrrear graves consecuencias.

$3^{\circ}$ Los excelentes resultados obtenidos usando la tiroxina como medicación de fondo les inducen a recomendar esta medicación para el tratamiento de la obesidad infantil." 12

En esta enumeración adquirían relevancia la identificación de la etapa previa a la pubertad como un período en el que era necesario adoptar controles más estrictos, la tipificación de la obesidad en los niños y la reivindicación de una especialidad para atenderla, y la utilización de hormonas en los tratamientos (Schere, 1938, p. 43). A los varones con obesidad hipofisiaria, que denominaban como genital, les administraban tiroxina porque consideraban que estos casos siempre iban acompañados de una insuficiencia genital, o hipogenitalismo. A la tiroxina se le atribuía el efecto de activar el metabolismo y de favorecer la maduración de los órganos genitales.

La vinculación de la obesidad con dificultades en el desarrollo sexual era compartida por otros especialistas como C. M. Pintos, quien reseñaba un artículo de I. Bram donde se advertía sobre la importancia de corregir la obesidad precoz para prevenir el desarrollo de la enfermedad de Frölich. Respecto de las niñas, afirmaban que el retardo del ciclo menstrual podía ser un indicador de obesidad genital. ${ }^{13}$ En un contexto internacional en el que la opoterapia y la hormonoterapia eran administradas para múltiples dolencias, consideraban que los extractos testiculares para ellos y la foliculina para ellas también podían ser utilizados como coadyuvantes.
En la definición de sus elementos constitutivos del síndrome incorporaban, en orden cronológico de aparición, a los factores ambientales, psiconeurológicos y somáticos. En las descripciones de las historias clínicas se consignaba una descripción más exhaustiva sobre las relaciones de pareja de la madre y el padre, o de sus personalidades, que sobre los aspectos somáticos del paciente. Esto se debía a que argumentaban que el origen del síndrome estaba en el ambiente. Respecto de estos factores, señalaban que la mayor parte de los pacientes presentaba una relación afectiva anormal cuantitativa y cualitativa con sus padres. Constataban que estos niños solían ocupar un lugar especial por ser hijos únicos, hijos menores o del medio, o por haber sido confiados al cuidado de matrimonios sin hijos o de mujeres solteras. También notaban que frecuentemente entre los padres de esos niños se había producido una ruptura del equilibrio afectivo parental por divorcio, viudez, o padre o madre inexistentes, o disminuidos desde el punto de vista moral. El estudio de las constelaciones familiares adquiría un peso importante en el diagnóstico porque entendían que el hijo único y el mayor solían correr más riesgos porque la personalidad se definía antes de los cinco años. Para fundamentar este supuesto se referían a trabajos sobre esquizofrénicos, epilépticos y superdotados, y especialmente al psicoanálisis. Además de las referencias freudianas, aludían a los expertos vinculados a la Ecole des Parents de París como Gilbert Robin o George Heuyer ${ }^{14}$.

Coincidían con Paul Clarence Oberndorf ${ }^{15}$ en que, más allá de los impulsos que actúan en el complejo de Edipo, la desviación en los sentimientos hacia los hijos depende del grado de satisfacción que encuentren los progenitores en su relación de pareja. El colecho y la cohabitación eran considerados peligrosos para el normal desarrollo de la sexualidad infantil, entendían que el compartir la cama con personas adultas podía generar una estimulación sexual inadecuada para los niños. La detección de prácticas que implicaran "caricias directas excesivas, seducciones o sobreestimulación" también era tenida en cuenta para diagnosticar condiciones ambientales nocivas. Consideraban que estas condiciones podían producir una hipertrofia de la capacidad sexual adquirida hasta entonces. Entendían que la bulimia, y las demás manifestaciones de la orientación oral, estaban determinadas por una regresión a una época en las que la satisfacción está escasamente reprimida, y donde el niño se mantenía como un sujeto pasivo y dependiente de su madre nutricia. Siguiendo estrictamente el esquema freudiano, afirmaban que el padre era el responsable de limitar la aspiración del niño de poseer totalmente a su madre. ${ }^{16}$ 
Luego de los factores ambientales, evaluaban los elementos psiconeurológicos que incluían el nivel mental (oligotimia y oligofrenia), la debilidad motriz, los rasgos esquizonoicos, las perturbaciones en el tono muscular, la preferencia hacia las actividades estáticas, la orientación oral y anal excesiva, la sexualidad y la aspiración profesional. Para la identificación de estos signos también se valían de conceptos psicoanalíticos que traducían en comportamientos visibles. Por ejemplo, entendían que el coleccionismo, la filatelia o la colombofilia eran evidencias de un carácter sádico anal. ${ }^{17}$

Sin hacerlo explícito siempre, aplicaban los Test de Feminidad-Masculinidad de Terman y Miles (1936). Los resultados esperables de los test de feminidad y masculinidad eran que los varones fueran activos, dominantes, directos, objetivos, independientes y racionales. Estas pruebas provenían de la psicología conductista y se realizaban para identificar tempranamente rasgos de personalidades "invertidas". El objetivo de estos estudios era prevenir la homosexualidad. Desde las propuestas de Terman y Miles, la familia y el matrimonio se convertían en el resguardo seguro para la profilaxis. Los médicos del consultorio de psico-neuro-endocrinología partían de estos supuestos cuando le otorgaban importancia a la falta de atracción por el deporte, a la preferencia por las actividades estáticas, al puerilismo y los temores excesivos, a la dependencia materna, o a las preferencias profesionales. ${ }^{18}$

La obesidad era tenida en cuenta en el último grupo de factores a estudiar: los somáticos. En esta instancia valoraban cuestiones generales como las alteraciones morfológicas, las osteocondrodistrofias, ${ }^{19}$ las perturbaciones de la visión, los disturbios vasomotores, los trastornos de la sudoración, las perturbaciones alérgicas (urticaria, eccema, coriza espasmódico, asma), entre otras. Entre las locales señalaban signos sexuales: micro o pequeño pene; testículos pequeños, ectópicos o mal descendidos; implantación del cabellos y monte de Venus feminoide; voz de timbre agudo o disfónico; dolores abdominales; sudoración de las manos y pies; pie plano; genu valgum; ginecomastia. Este hincapié en cuestiones genitales favorecía que sus presentaciones sobre obesidad infantil se confundieran con las de Síndrome de Frölich. ${ }^{20}$ Sin embargo, su interpretación sobre esta patología difería de la de Frölich y Babinski, que se centraban sólo en el cuadro somático y hacían especial hincapié en lo genital. Para los especialistas argentinos, el origen de la enfermedad era ambiental y esto se tornaba evidente cuando incorporaban como pacientes a las hermanas de los niños leídos con síndrome adiposo genital.
El supuesto origen ambiental les permitía aventurar que si el niño con síndrome adiposo genital tenía una hermana, nacida inmediatamente antes o después de él, era muy probable que padeciera el síndrome de virilización suprarrenal. Para tipificarlas de esa manera entendían que debía presentar una "evolución psicosomática hacia caracteres generales propios del varón." ${ }^{21}$. Compartían los criterios utilizados por Terman y Miles, pero explicaban que ellos habían podido detectarlas también en las revisiones clínicas. Entre sus características destacaban la virilización pilosa, el hábito androide, las perturbaciones foniátricas, el desarrollo exagerado de ciertos caracteres sexuales secundarios (clítoris, capuchón), la menarca precoz y los trastornos del ciclo, maduración esquelética precoz, fuerza muscular aumentada y trastornos del tono, senos con características particulares, o no desarrollados. Aunque en algunas de estas niñas podían identificar alteraciones en la glándula suprarrenal, relativizaban su importancia para dar centralidad a su ubicación en la constelación familiar y el colecho.

En los pacientes con síndrome adiposo genital no detectaban fallas glandulares a través de las radiografías de silla turca, ni con los exámenes de metabolismo basal. Ninguno de esos procedimientos permitía probar el origen glandular, pero las realizaban. En sus hermanas, tampoco podían identificar que su glándula suprarrenal estuviera alterada. En ambos, los indicadores radicaban en los aspectos visibles de un supuesto desarrollo sexual inadecuado. La posibilidad de que la obesidad de los varones presente ginecomastia (crecimiento de sus mamas), o de que las niñas tengan más vello corporal del esperado, podían interpretarse como síntomas de intersexualidad, u homosexualidad. La timidez, la preferencia por los juegos estáticos y la dependencia materna de los niños preocupaban tanto como su exceso de peso. La distribución de la grasa corporal de los varones era evaluada sólo como un indicador somático más, aunque era la causa inicial de la consulta. En su visita al consultorio se ponía en la mira su paso hacia la pubertad, y su heterosexualidad.

En la identificación del origen del síndrome pesaban las valoraciones de los médicos sobre cómo debían articularse los vínculos familiares, cómo debían representarse los roles maternos, cómo debía organizarse la vida doméstica. Las relaciones sexuales entre los adultos y el colecho de los niños entre sí, o con adultos, eran interpretados como patológicos, y patologizantes. Suponían que las familias podían generar neuropatías, y éstas alteraciones endocrinológicas. 
Los hijos únicos - aunque no fueran únicos - podían convertirse en pacientes con síndrome adiposo genital - aunque no fueran obesos -. La denominación creada para definir una enfermedad glandular era resignificada para denunciar los supuestos efectos de ciertos comportamientos familiares.

\section{EL SÍNDROME ADIPOSO GENITAL EN BARCELONA: RAYOS X Y MISTICISMO}

Los casos de distrofia adiposo-genital que presentaba Cervera i Astor eran de pacientes del Dispensario de Endocrinología y Sala de Dietética de la Cátedra de Terapéutica de la Facultad de Medicina de Barcelona, a cargo de Bellido. Las mediciones de metabolismo las realizaban en el Institut de Fisiología. En los papers que publicaba generalmente compartía su autoría con los técnicos que habían colaborado. En estos trabajos se puede identificar la estrecha relación de los laboratorios con la clínica. Su trayectoria como científico no impedía que reconociera los aportes de las observaciones y el análisis de los tratamientos que se realizaban en los consultorios. En este sentido, argumentaba que la fisio-patología humana podía prescindir de la llegada del hecho experimental abastecido por la experiencia del laboratorio. ${ }^{22}$

A partir del análisis de las historias clínicas publicadas, podemos conjeturar que las revisiones de los pacientes incorporaban múltiples intervenciones. Los antecedentes familiares eran enunciados solamente para referir si sus padres o hermanos eran obesos. El pasado del paciente incluía datos respecto de la crianza a pecho, el tiempo en el que comenzó a caminar o dentó, y especialmente su historial de enfermedades infecciosas porque consideraban que podían ser el origen de los trastornos hipofisiarios. Los exámenes incluían el peso, la altura, la evaluación de su silueta, de sus genitales, de la piel y la distribución del vello. Se valoraba si tenían genu valgum, problemas digestivos y respiratorios. Se analizaba la frecuencia de la orina, la fatiga, el metabolismo basal y los reflejos. Se incluía una radiografía de silla turca y en algunos casos se mencionaba una de cartílagos. En 1936, usaban diagnósticos de retraso mental a través de test psicólogicos Binet-Simons y perfil Rosolimo-Vermeylen, y el test de feminidad-masculinidad de Terman. ${ }^{23}$

La distrofia adipo-genital o síndrome de Frölich era entendida por Cervera i Astor como un trastorno hipofisiario que afectaba de manera idéntica a los dos sexos, y que tenía la particularidad de ser el que más claramente podía calificarse como puberal. A partir de su experiencia clínica, constataba que la mayoría de los casos se daban durante los cuatro o cinco años que preceden al desarrollo de la pubertad. Explicaba que solía interpretarse como un mal que aquejaba sólo a los varones por un error de observación médica, porque la adiposidad y el trastorno genital eran más visibles en ellos. Para describir los síntomas aludía a la analogía con las perturbaciones que presentaban los animales que habrían sufrido una hipofisectomía total o parcial. ${ }^{24}$

La definición predominante del paso de la niñez a la adolescencia hacía hincapié en los aspectos biológicos, en que se trataría de un momento en que comenzaría a manifestarse la aptitud para la reproducción (Borrás Llop, 1996). Cervera i Astor se inscribía en esta línea interpretativa. En 1933, publicó dos monografías sobre la pubertad donde destacaba el extraordinario interés biológico y médico de esta etapa porque en ella se daba la cesación funcional de un sistema glandular endocrino y el comienzo de otro. Entendía que la cadena endocrina que durante la infancia tenía como elementos primordiales al timus y a la pineal transfería paulatinamente su función a la tiroides y a la hipófisis. Este proceso convertía a esta fase vital en la más expuesta a peligros y más digna de observación. ${ }^{25}$

Sus ideas se nutrían de los saberes de la endocrinología y de la biotipología. Para explicar el crecimiento retomaba el aporte de Viola sobre el antagonismo ponderal morfológico, el de Godin sobre la ley de alternancia del desarrollo y el de Pende sobre la ley del desarrollo inversamente proporcional (Ballester Añon y Perdiguero Gil, 2003; Biernat, 2005; Rustoyburu, 2012a). Por eso, anticipaba que en la pubertad primero podía visibilizarse un engrosamiento del cuerpo y de la amplitud torácica, y que luego esto se interrumpiría por el crecimiento longitudinal. También constataba un aumento del tejido adiposo subcutáneo que topográficamente preveía que se distribuyera en zonas distintas en cada sexo.

Desde la perspectiva de Cervera i Astor, ese proceso era importante pero entendía que el cambio principal devenía por la definición de la diferencia sexual. Suponía que el nene y la nena presentaban características sexuales primarias o esenciales que los diferenciarían mutuamente. El testículo sería el órgano básico o fundamental del sexo masculino, y el ovario del femenino. En el momento del nacimiento, esos órganos tendrían todas las posibilidades dinámicas, pero en latencia. En la pubertad entendía que se daba el paso de la infancia a la juventud y el establecimiento de la diferencia sexual. Explicaba que se atravesaba un estado de lucha interna por la conquista de un tipo 
sexual definido. Advertía que, en la infancia, la morfología del cuerpo y de las extremidades, la voz y las manifestaciones psíquicas no estaban claramente diferenciadas por sexos. ${ }^{26} \mathrm{~A}$ los diez años, esperaba que se iniciara un desglose morfológico y espiritual que siguiera trayectorias divergentes cada vez más disímiles entre el nene y la nena. Retomando lo planteado por Steinach y Kun, a través de la observación de sujetos que habían sido capados antes de la pubertad y que no tenían desarrollados los signos sexuales secundarios, comprobaba que la emergencia de éstos se daba cuando la hipófisis anterior estimulaba la acción de los ovarios y los testículos. En este sentido, sus ideas se inscribían en las afirmaciones de quienes más tarde renovarían el campo de la endocrinología al otorgarle a la hipófisis un papel central en el desarrollo sexual (Fausto Sterling, 2006). A los signos sexuales secundarios los clasificaba como subsidiarios del aparato genital (pene, labios, vagina, útero, clítoris) y sus anexos (pelo pubiano, vesícula seminal, próstata y trompas), como extragenitales (mamas, pelo axilar y facial, morfología pélvica, caderas o muslos, evolución de la laringe), y de la zona psíquica (instinto de aproximación al sexo contrario, apetencia sexual, belicosidad masculina y recelo femenino). ${ }^{27}$

En sintonía con las ideas de la época (Fausto Sterling, 2006), la emergencia del sexo femenino la explicaba como el apagamiento de lo masculino. Retomaba lo planteado por Pende respecto del carácter virilizador de la glándula córtico-suprarrenal durante el momento previo a la pubertad para explicar que las niñas que tenían vello en todo el cuerpo y adiposidad varonil podían estar sufriendo de un tumor o una hipertrofia en esa glándula. Para que se estableciera claramente la apariencia femenina, la tiroides debía desensibilizar los tejidos ante la acción de esa hormona sexual. En los varones, en cambio, esto no debía suceder para que su masculinidad adquiriera intensidad y precisión. La adjudicación de esta acción a la córtico-suprarrenal significa que entendía que la definición de los caracteres secundarios no estaba determinada sólo por la acción de los ovarios o los testículos sino por una combinación endocrina múltiple. Suponía que un mismo elemento sexual podía recibir acciones estimulantes, inhibidoras y transformadoras en proporciones variables de distintas fuentes.

En coincidencia con el determinismo biológico que solía preponderar en las explicaciones de las psicopatologías (Comelles, 2007) y con la fuerte vinculación de la psicología con la endocrinología, interpretaba que el cambio en el psiquismo era una consecuencia de la transformación en la química corporal. Planteaba que si la pubertad de la materia no quedaba completada, es decir si el ovario y el testículo no llegaban a la cima de sus posibilidades endocrinas, el desarrollo psicológico tampoco se realizaba. Precisaba que las hormonas sexuales eran suficientemente capaces de afectar el cerebro. ${ }^{28}$ En los varones debía quedar claramente definida su mayor capacidad para resolver problemas matemáticos, una tendencia a la argumentación crítica, una lógica bien establecida en los temas de composición, una propensión a las ideas abstractas, una desmesurada inclinación hacia el exhibicionismo de su fuerza y la adopción de algunas conductas como fumar o "tirar flores" a las mujeres bien vestidas. En las niñas, en cambio, debía predominar su destreza por los trabajos manuales delicados y su facilidad memorística en las prácticas de enseñanza, una excelencia en su locuacidad, sentimentalismo, tendencia a la sugestión, imaginación fantasiosa y predilección por las ideas concretas. Creía que su transformación psíquica no tenía la teatralización de la del varón, porque la base del metabolismo de ellas presentaba deficiencias en los elementos minerales sanguíneos al iniciarse la excitación hipofisiaria sobre la glándula de la pubertad. ${ }^{29}$

La distrofia adipo-genital la definía como un trastorno de la hipófisis, en la región infundíbulo-talámica o cerca de los centros diencefálicos. Los medios tecnológicos de la época no le permitían probar que en todos los casos había un funcionamiento anormal de esa glándula. Por esto se valía de los aspectos visibles, y conjeturaba su origen por los supuestos resultados satisfactorios de las aplicaciones de rayos $X$ sobre esa zona. Planteaba que la silueta de los cuerpos de los enfermos era de un tipo de obesidad "neutra", pero en el varón hacía pensar en un ginandromorfismo. En todos los pacientes identificaba un retardo puberal notable, porque los caracteres secundarios estaban ausentes o evolucionaban lentamente. En la presentación teórica, también consideraba que a veces se leía como feminizada la psiquis de los varones porque malinterpretaban su actitud infantil. Al mismo tiempo, advertía que la inteligencia solía ser clara y ágil.

Al diagnosticar como adiposo-genitales a los niños y las niñas que sólo presentaban algunos síntomas y signos visibles, transformaba al síndrome en una patología frecuente. Planteaba que no era una enfermedad que se caracterizara por los trastornos cardiovasculares, ni tampoco encontraba datos de interés en los análisis de orina. Aunque entendía que podían manifestar poliuria abundante (diabetes insípida), trastor- 
nos del crecimiento, hipotermia, somnolencia, atraso mental y abulia, pereza y pillería. En el consultorio realizaban exámenes para detectar esos posibles signos, y se hacían mediciones del metabolismo basal para calcular las dosis de tiroxina que implementaría. Consideraba necesario realizar radiografías de la silla turca para determinar si existía alguna tumoración hipofisaria, aunque en todos los casos que presentó mostraban dimensiones normales. Para establecer la etiología, recomendaba además tener en cuenta todos los antecedentes. Manifestaba que no era raro descubrir una lúes hereditaria o adquirida durante la lactancia mercenaria, pero que generalmente constataba un historial de patologías infantiles en el cual sobresalían las fiebres eruptivas o algún proceso infeccioso como paperas, reumatismo y estafilococo - estreptococos.

El desarrollo de los signos sexuales primarios y secundarios era un aspecto central de su argumentación cuando tenía que probar la curación. Aunque este aspecto no solía ser el motivo inicial de la llegada al consultorio, a excepción de la historia en la que un niño fue derivado por un médico inspector cuando fue sometido a una revisión para ingresar como aprendiz de cerrajero, o en la que el joven es llevado a la consulta porque está cansado de las burlas de sus compañeros de trabajo. ${ }^{30}$ Creía que el eunucoidismo que visualizaba en sus pacientes era un efecto secundario, no presuponía una mala estructuración de la glándula sexual. Con los casos de curaciones demostraba que el aspecto deficitario de la zona genital dejaba de presentarse cuando las hormonas prehipofisiarias arribaban al parénquima del testículo o del ovario en cantidades suficientes como para provocar una actividad incretora de aquellos órganos específicos y fundamentales de la sexualidad. ${ }^{31}$

Cervera i Astor, desde su primera monografía donde se alineó a la perspectiva de Gley, se mostró crítico de la proliferación de la opoterapia. En sus presentaciones, solía denunciar la impericia de algunos laboratorios en la extracción de las hormonas. Especialmente advertía sobre el carácter erróneo del supuesto de que cada tejido podía dar origen a una sustancia diferente. Sin embargo, en su consultorio administraba glicéridos y extractos de tiroides, cuando el metabolismo era bajo.

En su práctica clínica, ante los síndromes hipofisiarios, prefería los tratamientos con rayos $X$ proyectados sobre distintas zonas de la cabeza de sus pacientes. Los resultados sobre las terapias con rayos fueron presentados en las sesiones científicas de la Societat Catalana de Biología, ${ }^{32}$ en un escenario en el que proliferaban los trabajos sobre los beneficios de las ra- diaciones para mejorar la leche materna y para tratar el coqueluche; y en el que las páginas de las revistas médicas reproducían publicidades de institutos que ofrecían el uso de esas tecnologías a los médicos. En 1934, presentó veintidós casos de pacientes tratados bajo este régimen y afirmó que había curado a los que padecían Síndrome de Simmons, mejorado a los de diabetes insípida y sanado parcialmente a los de síndrome adiposo genital (Froëlich). ${ }^{33}$

Las pruebas de la curación de los varones con síndrome adiposo genital que presentaba en las revistas científicas eran fotografías de niños desnudos donde se podía apreciar que adelgazaron y se desarrollaron sus signos sexuales secundarios. También hacía hincapié en las transformaciones en la personalidad y en el comportamiento, que hoy podríamos interpretar como la expresión de género. Destacaba el carácter "místico feminoide" o de "religiosidad femenina", que luego de la curación desaparecía. ${ }^{34}$

En 1936, su perspectiva incorporó otros saberes. Presentó cinco nuevos casos y definió al Síndrome de Froehlich como "síndrome de retardo puberal". ${ }^{35}$ Este cambio en la denominación podría ser interpretado en relación con el debate que entablaba con Bauer, quien planteaba que los rayos $\mathrm{X}$ no producían ningún efecto $\mathrm{Y}$ que esa patología que describía Cervera i Astor se resolvía espontáneamente. Éste, en cambio, entendía que si no se intervenía podía establecerse un eunucoidismo permanente. Además, reformulaba la hipótesis de Froehlich respecto del origen de la enfermedad, como exclusivamente producida por un déficit prehipofisiario. Interpretaba que los resultados de los tratamientos le permitía suponer un mecanismo más complejo, sin negar la influencia de la hipófisis creía que había que considerar el peso de la tiroides y de las hormonas gonadales. En los casos que presentaba reforzó descripciones en las que se destacaba la obesidad y los genitales no desarrollados, y la personalidad "femenina".

En las historias que narró en 1936, los padres eran incluidos en las descripciones para identificar si también padecían obesidad. Sólo en uno sólo de los casos explicitaron que eran nerviosos para dar cuenta de cómo habían transgredido las indicaciones de los médicos, consultando a un naturista. ${ }^{36}$ Las hermanas sólo eran mencionadas si padecían obesidad hipofisiaria. En la explicación teórica de Cervera i Astor, las niñas también podían ser diagnosticadas con distrofia adiposa-genital. Sin embargo, en los ejemplos que presentó en sus publicaciones, las historias de ellas eran menos numerosas y estaban asociadas a otros padeceres como la tuberculosis. ${ }^{37}$ 
En los diagnósticos de las causas del síndrome adiposo-genital realizados por Cervera i Astor, las relaciones familiares no ocupaban un papel central. Sin embargo, ese tipo de valoraciones no estaban ausentes en otros ámbitos de Cataluña donde el psicoanálisis y la psicología habían logrado cierta legitimación. En los dictámenes del Tribunal Tutelar per a Nois, estos aspectos adquirían mayor protagonismo. En diciembre de 1925, en Infantia Nostra, se reprodujo un dictamen médico-psicológico de dos niñas en los que la herencia adquiría fuerza etiológica y la distrofia adiposogenital podía ser diagnosticada sólo a partir de aspectos visibles. Se convertía en una afección que podía explicar no sólo la obesidad sino también un supuesto retardo mental. En la presentación del experto del Tribunal se puede identificar la legitimación de los tratamientos con opoterapia, la ambigüedad que podía adoptar el concepto síndrome adiposo genital y la aceptación de que podía curarse espontáneamente. Aunque, al igual que Cervera i Astor, suponía que eso podía ser arriesgado. ${ }^{38}$

Las lecturas del síndrome adiposo genital realizadas por Cervera i Astor resultan interesantes porque formaron parte de la controversia internacional. Sus casos fueron publicados en revistas prestigiosas y discutidos por los referentes de la endocrinología de ese momento, y formaron parte de una época de importante desarrollo de la radiología. Sin embargo, es necesario también valorar que las apelaciones a ese síndrome habían trascendido a los casos con alteraciones glandulares como las que habían probado Froelich y Babinski. Al no disponer de los medios para probar un daño en la hipófisis, pudo apelarse a este concepto para intervenir en los cuerpos de todos los niños obesos con un supuesto retardo puberal. Las valoraciones sobre estos casos dejan traslucir nociones respecto de qué cuerpos eran interpretados como normales y qué se entendía como apropiado para un joven y una joven. El determinismo biológico respecto de la sexualidad del que partía Cervera i Astor no le impedía incorporar interpretaciones de género sobre los comportamientos y las actitudes de los varones que atendía en su consultorio. El "misticismo feminoide" también podía curarlo con rayos $X$.

\section{CONSIDERACIONES FINALES}

Desde los estudios de género se han analizado las ideas sobre la química corporal porque en ella los científicos buscaron ciertas claves para explicar el proceso de diferenciación sexual. Desde distintas aproximaciones, se ha planteado una correlación entre las lecturas en clave de disputas entre constelaciones hormonales y los escenarios políticos de las reivindicaciones feministas (Oudshoorn, 1994; Fausto Sterling, 2006). Los enfrentamientos en las calles parecieron trasladarse a las miradas sobre los cuerpos. La proliferación de las comunicaciones también parece haber condicionado a los autores ingleses que denominaron como "mensajeros químicos" a las sustancias de elaboración endocrina que establecen interrelaciones orgánicas (Preciado, 2008).

Las lecturas sobre la transición de la infancia a la pubertad de Cervera i Astor se inscribían explícitamente en esa línea interpretativa que podía ver a las glándulas como actores de una disputa por el establecimiento de un sexo. En sus textos se vislumbra la complejidad que adquiría la endocrinología al reconstruir el entramado glandular. Entendía que la diferencia entre los sexos se establecía por las gónadas, pero le otorgaba a la hipófisis un lugar central en su desarrollo y funcionamiento. Estos supuestos le permitían construir argumentos respecto de la necesidad de identificar y curar el síndrome adiposo genital, aunque no pudiera comprobar su origen hipofisiario. La legitimidad de sus argumentos se sustentaba en las expectativas que generaba la difusión de las terapias con rayos $X$ y en que sus casos podían insertarse en una controversia científica internacional.

Arnaldo Rascovsky, Samuel Schere, Enrique Pichon Riviere, Juan Carlos Perellano, Jaime Salzman, Teodoro Sholossberg y Gregorio Ferrari Hardoy no lograron insertar sus casos en el escenario internacional. La resonancia de sus trabajos no devenía de sus experiencias como endocrinólogos, ni del aparente éxito de sus tratamientos. Aunque en las sesiones científicas de la Sociedad Argentina de Pediatría eran cuestionados, la legitimidad de sus argumentos se anclaba en su pertenencia a la sala del Hospital de Niños que dirigía Aquiles Gareiso y en que supieron combinar las preocupaciones sociales en torno de la desnatalidad con las expectativas que despertaba el psicoanálisis. Las presentaciones de los casos de síndrome adiposo genital en la Sociedad Argentina de Pediatría se inscriben en el proceso de conformación institucional de la Asociación Psicoanalítica Argentina y de legitimación de estos saberes en el escenario médico local. En las transcripciones de las sesiones científicas se evidencian cuestionamientos de colegas que descreían que la causa de dicho síndrome - o de la epilepsia, como argumentaba Rascovsky - fuera el colecho. La psicología conductista solía generar menos incomodidades que las propuestas de Sigmund Freud o de Melanie 
Klein que transgredían ciertos principios morales sobre la sexualidad infantil (Dagfal, 2009). Cuando estas lecturas se difundieron, en la década de 1960 durante el boom del psicoanálisis, la experiencia del consultorio de psico-neuro-endocrinología perdió su carácter polémico y fue interpretada como un hito fundador de la medicina psicosomática en ese país.

El carácter social de los conocimientos científicos impone problematizar estos escenarios institucionales y académicos donde fueron producidos (Latour y Woolgar, [1979] 1995; Knoor-Cetina, 2005). Estas consideraciones además exigen insertarlos en el momento histórico en el que se inscribían. En este sentido, una valoración de la importancia de estos discursos no puede eludir su relación con el proceso de medicalización de la maternidad y de la infancia. A fines del siglo XIX y principios del siglo XX, la crianza de los niños, los comportamientos familiares y la sexualidad se convirtieron en áreas de incumbencia del saber médico. Los doctores pudieron intervenir en la educación, las relaciones parentales, la lactancia, los partos y la alimentación de los niños. La decisión de las madres y los padres de llevar a sus hijos o hijas al consultorio se explica por la legitimación de la opinión de los pediatras.

La construcción de los discursos médicos tampoco resultó ajena a la configuración de una matriz de pensamiento dicotómica. En las interpretaciones sobre la obesidad infantil como síndrome adiposo genital se

\section{NOTAS}

1. Actualmente, los endocrinólogos se refieren al síndrome Babinski-Frölich como el constituido por la asociación de una obesidad considerable, predominante en el tronco y en la raíz de los miembros, y de una distrofia genital que, en el individuo joven, se traduce por la detención del desarrollo de los órganos sexuales, y en el adulto por amenorrea en la mujer e impotencia en el hombre, y en ambos sexos por la alteración e incluso la inversión de los caracteres sexuales secundarios. Este síndrome se considera ligado a una lesión de la hipófisis o de la región infundibulotuberiana.

2. Correspondencia mantenida con Bernardo Houssay. Archivo Leandre Cervera i Astor. Biblioteca Nacional de Cataluña.

3. Algunos de ellos participaron de la fundación de la APA. Arnaldo Rascovsky (1908-1995) fue un médico, psiquiatra y psicoanalista argentino que adquirió amplia difusión a partir de sus estudios sobre el filicidio, una teoría que intentaba dar cuenta del asesinato de los jóvenes y los niños por el mundo adulto. Es reconocido como uno de los pediatras psicosomáticos más importantes de Argentina, por su presencia en los medios de comunicación y porque participó de la creación de la APA y de la Asociación Endocrinológi- pusieron en juego discursos en torno de la diferencia entre los sexos, los comportamientos y las expresiones de género, la infancia, la familia y la sexualidad. En Barcelona y en Buenos Aires se tornaron explícitas ciertas ideas sobre la feminidad y la masculinidad, y sobre la niñez y la pubertad. En los consultorios, se usaron los saberes disponibles para diagnosticar y corregir a quienes transgredían la heteronormatividad y la diferencia sexual.

\section{AGRADECIMIENTOS}

Este trabajo fue realizado durante una estadía posdoctoral en el Departament d'Antropologia Social i Història d'Amèrica i Àfrica de la Universitat de Barcelona, bajo la dirección de Joan Bestard Camps, financiada por el Consejo Nacional de Investigaciones Científicas y Técnicas (CONICET-Argentina). Agradezco sus valiosas orientaciones como así también las interpelaciones recibidas en el seminario interno del Grup de Recerca en Antropologia del Parentiu i el Patrimoni. Mi gratitud se extiende a los aportes de Jon Arrizabalaga y Josep Comeilles que han resultado fundamentales para la búsqueda de fuentes y bibliografía específica. La investigación en Argentina ha sido sostenida con el PICT-Joven "Ciencia, Medicina y Género. Campo médico y producción de saberes sobre hormonas sexuadas, en Argentina en la segunda mitad del siglo XX" de la Agencia Nacional de Promoción Científica y Tecnológica.

ca Argentina. Ingresó en 1932 como practicante del Servicio de Neuropsiquiatría y Endocrinología del Hospital de Niños. Enrique Pichon Riviere (1907-1977) fue un médico psiquiatra suizo-argentino que ha sido considerado uno de los introductores del psicoanálisis en Argentina. Sus aportes fundamentales se dieron en el ámbito de la psicología social, por su teoría de grupo. Fue fundador de la Primera Escuela Privada de Psicología Social y del Instituto Argentino de Estudios Sociales (IADES). Enrique Ferrari Hardoy era médico foniatra, poco tiempo después de la fundación de la APA se trasladó a Estados Unidos. En la década de 1960, regresó a Buenos Aires pero no se reincorporó a la institución.

4. La eficacia de su tratamiento fue aceptada por Allen Winter de Boston, Joffa de Melbourne, Campbell de Wellington, Mazer y Goldstein de Filadelfia, y Carulla de España.

5. William Healy (1869-1963) fue un psiquiatra y criminólogo estadounidense. Fue el creador de las primeras clínicas de orientación infantil para tratar niños con síntomas psicopatológicos. Su propuesta formó parte de la renovación psiquiátrica que tendía a no aislar a los pequeños del ambiente familiar. Su enfoque pretendía el trabajo en equipo 
y el abordaje multidimensional. Realizó importantes contribuciones para la introducción del psicoanálisis en su país.

6. Édouard Pichon (1890-1940) fue pediatra, cofundador de la Sociedad de Psicoanálisis Francesa, vinculado a René Laforgue y Francoise Doltó. Fue partidario de Anna Freud en la Querella con Melanie Klein, considerando que el psicoanálisis de niños debía estar vinculado a la autoridad educativa. Propuso la creación de una síntesis entre los aportes de Pierre Janet, Sigmund Freud, Jean Piaget, Alfred Binet et Henri Wallon, llamada psicopedéutica.

7. Petre, Alejandro; Rascovsky, Arnaldo (1940), "La consulta psico-neuro-endocrinológica", Archivos Argentinos de pediatría, XI (14), pp. 281-285, p. 281.

8. Los estudios universitarios de psicología, en Argentina, se iniciaron durante el peronismo y se multiplicaron en la década de 1950 .

9. Florencio Escardó (1904-1992) fue un prestigioso pediatra argentino. Alcanzó reconocimiento por ser coautor, junto a Aquiles Gareiso, del primer manual de neuropsiquiatría infantil de Latinoamérica. Fue un referente de la pediatría psicosomática, Profesor Titular de la Segunda Cátedra de Pediatría de la Facultad de Ciencias Médicas de la Universidad de Buenos Aires y Jefe de Servicio en el Hospital de Niños de Buenos Aires. También fue Decano de la misma facultad y vicerrector de la Universidad. Desde muy joven ocupó espacios en los medios de comunicación y actuó como consejero en temáticas de crianza.

10. Larguía, Alfredo (1938), “N. Talbot. Determinación de la obesidad por el coeficiente creatinúrico. "Am. J. Dis. Of. Chidr." 1938: 55: 42.", Archivos Argentinos de Pediatría, Año IX (2), p. 714

11. Esta psicoanalista norteamericana, nacida en Alemania, fue una de las primeras en investigar sobre anorexia nerviosa y en relacionarla con las prácticas de los padres. En este sentido, entendía que esta afección podía ser el resultado de la educación durante la primera infancia, cuando los niños aprendían a desoír la fisiología natural del hambre. Creó el término "Eat Like Daddy Syndrome" para referirse a los hábitos de los pequeños que imitan al padre que come en exceso porque ven que su esposa lo elogia.

12. $V^{\circ}$ Congreso Nacional de Medicina, Rosario 1934. Resumen de los trabajos presentados y discusiones correspondientes. Dr. Benito Soria (de Córdoba). Anomalías constitucionales del lactante y regímenes alimentarios. Archivos Argentinos de Pediatría, V (3), pp. 681-686. p. 685.

13. Pintos, C. M. (1938), "I. Bram. Obesidad precoz. "Archiv. of Pediatrics", 1938: 55: 381", Archivos Argentinos de Pediatría, IX (2), p. 714.

14. Jacques Donzelot (1979) ha analizado esta experiencia como un mecanismo de normalización social que introdujo al psicoanálisis en el escenario francés. Ver también: (Ohayon,
2000). Rascovsky, Arnaldo; Schlossberg, Teodoro; Gregorio, Ferrari Hardoy; Olariaga, Tomás (1940), "Cuadros de desequilibrio entre maduración, crecimiento y sublimación en niños de edades similares.", Archivos Argentinos de Pediatría. XI (14), pp. 642-654.

15. Paul Clarence Oberndonf fue un reconocido psiquiatra y psicoanalista norteamericano. Fue alumno de Emil Kraepelin, y después uno de los fundadores, junto con Abraham Arden Bril, de la New York Psychoanalytic Society (NYPS). Más tarde ocupó dos veces la presidencia de la American Psychoanalytic Association (APsaA). Era un representante más ortodoxo del freudismo norteamericano.

16. Rascovsky, Arnaldo; Pichon Riviere, Enrique; Salzman, Jaime (1940), "Elementos constitutivos del síndrome adiposo genital prepuberal en el varón." En Archivos Argentinos de Pediatría, XI (14), pp. 391-400.

17. Rascovsky, Arnaldo; Pichon Riviere, Enrique; Salzman, Jaime (1940), "Elementos constitutivos del síndrome adiposo genital prepuberal en el varón." En Archivos Argentinos de Pediatría, XI (14), pp. 391-400.

18. Rascovsky, Arnaldo; Salzman, Jaime (1940), "Estudio de los factores ambientales en el síndrome adiposo-genital en el varón", Archivos Argentinos de pediatría, XI (14), pp. 527-537.

19. Este término se refería a una enfermedad conceptualizada así por el pediatra uruguayo Luis Morquio en 1929. Se trata de una afección hereditaria en los huesos, cartílados, tendones y otros tejidos caracterizada por la acumulación de mucopolisacáridos.

20. Rascovsky, Arnaldo; Salzman, Jaime (1940), "Estudio de los factores ambientales en el síndrome adiposo-genital en el varón", Archivos Argentinos de pediatría, XI (14), pp. 527537. Rascovsky, Arnaldo; Salzman, Jaime (1941), Estudio de los factores ambientales en el síndrome adiposogenital del varón. (3a comunicación). Archivos Argentinos de Pediatría, XV (16), pp. 342-356.

21. Rascovsky, Arnaldo; Schlossberg Teodoro; Ferrari Hardoy, Gregorio (1940), "Síndrome de virilización suprarrenal en niñas", Archivos Argentinos de Pediatría, XI (14), pp. 377-398.

22. Cervera, Leandre; Torres-Carreras, Ramón (1928), "Sindrome de Frohlich i raigs X", Monitor Médic, 1 (1). También publicado en Treballs de la Societat de Biologia de Barcelona. Any 1928. Cervera, Leandre; Torres i Carreras, Ramón (1928 y 1929), "Síndrome de Frölich i raigs X", Treballs de la Societat de Biologia, 12, pp. $71-75$.

23. Cervera Leandre; Folch Albert; Bonaventura, Benages (1936), "Les hipòfisiopaties en clínica. Nova casuística comentada. (Nota sobre terapéutica)", Medicina Catalana, IV (35-36), pp 135-172.

24. Cervera, Leandre (1933), "La pubertat patològica", Monografies Médiques, VIII (76). 
25. Cervera, Leandre (1933), "La pubertat patològica", Monografies Médiques, VIII (76). Cervera, Leandre (1933), “La pubertat normal", Monografies Médiques, VIII (73).

26. Estos planteamientos de Cervera coincidían con cierto consenso entre los fisiólogos respecto de la bisexualidad inicial de los organismos. Sobre las ideas de Marañón ver: Castejón, 2013; Glick, 2005.

27. Cervera, Leandre (1933), "La pubertat normal”, Monografies Médiques, VIII (73).

28. También interpretaba que las obras de arte eran producto del aparato psico-físico. "Todo el sustratum de la estética: volúmenes y contornos, valores de luz y colores, continentes y contenidos, tonalidades, timbre, etc., pueden considerarse como resultados de procesos psicológicos debidos al trabajo de células ganglionares y fibras nerviosas, músculos y tendones; a leyes de irritación y de irradiación nerviosa."

29. Cervera, Leandre (1933), "La pubertat normal”, Monografies Médiques, VIII (73). Cervera, Leandre; Folch, Alberto; Bonaventura, Benages (1934), "Consideracions a propósit de 22 casos d'hipòfisopaties tractats. (Nota terapéutica)." Medicina Catalana, II (11), pp. 153-176. Cervera, Leandre; Folch, Albert; Bonaventura, Benages (1936), "Les hipòfisiopaties en clínica. Nova casuística comentada. (Nota sobre terapéutica).", Medicina Catalana, IV (35-36), pp.135-172.

30. Cervera, Leandre; Folch, Alberto; Bonaventura, Benages (1934), "Consideracions a propósit de 22 casos d'hipòfisopaties tractats. (Nota terapéutica)." Medicina Catalana, II (11), pp. 153-176.

31.Cervera, Leandre; Folch, Alberto; Bonaventura, Benages (1934), "Consideracions a propósit de 22 casos

\section{BIBLIOGRAFÍA}

Agüero, Abel; Milanino, Ana Elizabet; Bortz, Jaime Elías; IsolabeIla, Marcos (2012), "Precursores de la Antropometría Escolar en la ciudad de Buenos Aires: Luis Cassinelli, Genaron Sisto, Juan. P. Garrahan, Saúl Bettinotti y Cornejo Sosa", Ëa Journal, 4 (1). [en línea], disponible en: http://www.ea-journal.com/ images/stories/Arts0401/Articulo_-_Aguero_et_al-Precursores.pdf [consultado el 18/05/2015].

Agüero, Abel; Milanino, Ana Elizabet; Sánchez, Norma Isabel; Kohn Loncarica, Alfredo (2011), "Salud Escolar 1880-1900. ¿Un instrumento de control social?”. En: Sánchez, Norma Isabel (Comp.), Historia de la niñez en la Argentina. (18801900) Una mirada médica y socio cultural, Buenos Aires, Dunken, pp. 15-91.

Aguirre Marco, Carla (2013), "El significado histórico de las aportaciones de Marañón a la endocrinología internacional", Arbor. Ciencia, Pensamiento y Cultura, 189 (759). [en línea] doi: http://dx.doi.org/10.3989/arbor.2013.759n1002. [consultado el 02/10/2014]. d'hipòfisopaties tractats. (Nota terapéutica)." Medicina Catalana, II (11), pp. 153-176.

32. Cervera, Leandre y R. Torres-Carreras (1928). "Sindrome de Frohlich i raigs X" en Monitor Médic. Barcelona. 1 (1). También publicado en Treballs de la Societat de Biologia de Barcelona. Any 1928.

33. Cervera, Leandre; Folch, Albert; Bonaventura, Benages (1936), "Les hipòfisiopaties en clínica. Nova casuística comentada. (Nota sobre terapéutica).", Medicina Catalana, IV (35-36), pp.135-172.

34. Cervera, Leandre; Torres Carreras, Ramón; Bosch-Sola, Pedro (1932). "Hypofonctionnement hypophyso-thyroïdien et Syndrome Adiposo-genital", Revue Francaise d'Endocrinologie, 10 (2), pp. 143-155.

35.Cervera, Leandre; Folch, Albert; Bonaventura, Benages (1936), "Les hipòfisiopaties en clínica. Nova casuística comentada. (Nota sobre terapéutica).", Medicina Catalana, IV (35-36), pp.135-172.

36.Cervera, Leandre; Folch, Albert; Bonaventura, Benages (1936), "Les hipòfisiopaties en clínica. Nova casuística comentada. (Nota sobre terapéutica).", Medicina Catalana, IV (35-36), pp.135-172.

37. Cervera, Leandre; Folch, Alberto; Bonaventura, Benages (1934), "Consideracions a propósit de 22 casos d'hipòfisopaties tractats. (Nota terapéutica)." Medicina Catalana, II (11), pp. 153-176.

38. “Dictámenes del Tribunal Tutelar para Niños. Dictamen médico-psicológico de las niñas J. y M. X.", Infantia Nostra, IV (35), Diciembre de 1925, 96.

Aresti, Nerea (2001), Médicos, Donjuanes y Mujeres Modernas: los ideales de feminidad y masculinidad en el primer tercio del siglo XX. Bilbao: Universidad del País Vasco.

Ballester Añon, Rosa y Perdiguero Gil, Enrique (2003), “Ciencia e ideología en los estudios sobre crecimiento humano en Francia y en España (1900-1950)", Dynamis, 23, pp. 61-84.

Barone, Roxana (2009), Arnaldo Rascovsky. El gran comunicador del psicoanálisis, Buenos Aires, Capital Intelectual.

Biernat, Carolina (2005), "La eugenesia argentina y el debate sobre el crecimiento de la población en los años de entreguerras", Cuadernos del Sur Historia, 34, pp. 251-273.

Borrás Llop, José María (comp.) (1996), Historia de la infancia en la España contemporánea 1834-1936, Madrid, Ministerio de Trabajo y Asuntos Sociales.

Buch, Adolfo (2006), Forma y función de un sujeto moderno. Bernardo Houssay y la fisiología argentina (1900-1943), Bernal, UNQUI. 
Carpintero, Enrique; Vainer, Alejandro (2004), Las huellas de la memoria. Psicoanálisis y Salud Mental en la Argentina de los '60 y '70. (Tomo I: 1957-1969), Buenos Aires, Topía.

Castejón Bolea, Ramón (2013), “Marañón y la identidad sexual: biología, sexualidad y género en la España de la década de 1920", Arbor. Ciencia, Pensamiento y Cultura, 189 (759). [en línea] doi: http://dx.doi.org/10.3989/arbor.2013.759n1004 [consultado el 02/10/2014]

Cepeda, Agustina (2011), "En los tiempos del test del sapo: justicia, aborto y políticas de población en Argentina a mediados del siglo XX", Revista de Estudos Universitarios, 37 (1), pp. 243-265.

Cervera, Leandre (1933), "La pubertat normal”, Monografies Médiques, VIII (73).

Cervera, Leandre (1933), "La pubertat patològica”, Monografies Médiques, VIII (76).

Cervera, Leandre; Torres-Carreras, Ramón (1928), "Sindrome de Frohlich i raigs X", Monitor Médic, 1 (1).

Cervera, Leandre y Torres i Carreras, Ramón (1928 y 1929), "Síndrome de Frölich i raigs X", Treballs de la Societat de Biologia, 12, pp. $71-75$.

Cervera, Leandre; Torres-Carreras, Ramón; Bosch-Sola, Pedro (1932). "Hypofonctionnement hypophyso-thyroïdien et Syndrome Adiposo-genital", Revue Francaise d'Endocrinologie, 10 (2), pp. 143-155.

Cervera, Leandre; Folch, Alberto; Bonaventura, Benages (1934), "Consideracions a propósit de 22 casos d'hipòfisopaties tractats. (Nota terapéutica)." Medicina Catalana, II (11), pp. 153-176.

Cervera, Leandre; Folch, Albert; Bonaventura, Benages (1936), "Les hipòfisiopaties en clínica. Nova casuística comentada. (Nota sobre terapéutica)", Medicina Catalana, IV (35-36), pp 135-172.

Cleminson, Richard y Vázquez García, Francisco (2009), "Breast, Hair and Hormones: The Anatomy of Gender Difference in Spain, 1880-1940", Bulletin of Spanish Studies, 86 (5), pp. 627-652.

Collins, Harry [1975] (1995), "Los siete sexos: estudio sociológico de un fenómeno, o la replicación de los experimentos en física". En: Iranzo, Manuel; Blanco, Manuel; Gonzalez de la Fe, Teresa; Torres, Cristóbal; Cotillo, Alberto (coord.), Sociología de la Ciencia y la Tecnología, Madrid, CSIC, pp. 141-160.

Comelles, Josep (2007), “Cultura, sociedad y psiquiatras en España", Frenia, VII (1), pp. 7-24

Dagfal, Alejandro (2009), Entre París y Buenos Aires. La invención del psicólogo (1942-1966), Buenos Aires, Paidós.
Del Cura González, Mercedes y Huertas, Rafael (2004), “Medicina y sexualidad infantil en la España de los años treinta. La aportación del psicoanálisis a la pedagogía sexual.", Hispania, LXIV (218), pp. 987-1001, [en línea] doi: http://dx.doi. org/10.3989/hispania.2004.v64.i218.176 [consultado el 29/10/2014].

Dictámenes del Tribunal Tutelar para Niños. Dictamen médicopsicológico de las niñas J. y M. X.", Infantia Nostra, IV (35), Diciembre de 1925, 96.

Didi-Huberman, Georges (2007), La invención de la hysteria. Charcot y la iconografía fotográfica de la Salpêtrière, Madrid, Cátedra.

Donzelot, Jacques (1979), La policía de las familias, Valencia, Pretextos.

Eraso, Yolanda (2007), “Biotypology, Endocrinology, and Sterilization: The Practice of Eugenics in the Treatment of Argentinian Women during the 1930s", Bulletin of the History of Medicine, 81 (4), pp. 793-822.

Fausto Sterling, Anee (2006), Cuerpos sexuados. La política de género y la construcción de la sexualidad, Madrid, Melusina.

Foucault, Michel (1976) [2005], Historia de la sexualidad: la voluntad del saber, Buenos Aires, Siglo XXI.

Glick, Thomas (1976), “On the Diffusión of a New Specialty: Marañón and the "Crisis" of Endocrinology in Spain.", Journal of the History of Biology, 9 (2), pp. 287-300.

Glick, Thomas (2005), "Marañón, Intersexuality and the Biological Construction of Gender in 1920s Spain", Cronos, 8 (1), pp. 121-137.

Gracia-Arnaiz Mabel (ed.) (2012), Pobres joves grassos. Obesitat $i$ itineraris juvenils a Catalunya, Tarragona, Publicaciones URV.

Huertas, Rafael y Novella, Enric (2013), "Sexo y Modernidad en la España de la Segunda República. Los discursos de la ciencia", Arbor. Ciencia, Pensamiento y Cultura, 189 (764), [en línea] doi: http://dx.doi.org/10.3989/arbor.2013.764n6013 (consultado el 29/10/2014).

Hurtado Diego y Fernández María José (2013), “Institutos privados de investigación "pura" versus políticas públicas de ciencia y tecnología en la Argentina (1943-1955)", Asclepio. Revista de Historia de la Medicina y de la Ciencia. 65(1). [en línea] doi: http://dx.doi.org/10.3989/asclepio.2013.10 (consultado el 16/07/2015)

Knorr-Cetina, Karin (2005), La fabricación del conocimiento. Un ensayo sobre el carácter constructivista y contextual de la ciencia, Quilmes, UNQUI.

Laqueur, Thomas (1990), La construcción del sexo. Cuerpo y género desde los griegos hasta Freud, Valencia, Cátedra. 
Larguía, Alfredo (1938), “N. Talbot. Determinación de la obesidad por el coeficiente creatinúrico. "Am. J. Dis. Of. Chidr." 1938: 55: 42.", Archivos Argentinos de Pediatría. IX (2). p. 714.

Latour, Bruno y Woolgar, Steve [1979] (1995), La vida en el laboratorio. La construcción de los hechos científicos, Madrid, Alianza.

Ohayon, Annick (2000), "L'éducation des parents: histoire d'une illusion", La lettre du grape. Revue de l'enfance et de I 'adolescence, 41, pp. 83-91.

Orozco Acuaviva, Antonio (1999), Historia de la endocrinología española, Madrid, Ediciones Díaz Santos.

Ortiz Gómez, Teresa (1993), "El discurso médico sobre las mujeres en la España del primer tercio del siglo XX". En López Beltrán, María Teresa (ed.), Las mujeres en Andalucía. II Encuentro Interdisciplinar de Estudios de la Mujer en Andalucía. Vol. 1, Málaga, Diputación Provincial, pp. 107-138.

Oudshoorn, Nelly (1994), Beyond the Natural Body. An Archeology of Sex Hormones, London and New York, Routledge

Petre, Alejandro y Rascovsky, Arnaldo (1940), "La consulta psico-neuro-endocrinológica.", Archivos Argentinos de Pediatría, XI (14), pp. 281-285.

Pintos, C. M. (1938), "I. Bram. Obesidad precoz. "Archiv. of Pediatrics", 1938: 55: 381", Archivos Argentinos de Pediatría, IX (2), p. 714

Plotkin, Mariano (2003), Freud en las pampas. Orígenes y desarrollo de una cultura psicoanalítica en la Argentina (1910 -1983), Buenos Aires, Sudamericana.

Plotkin, Mariano (2006), "El psicoanálisis antes del boom”. En Biagini, Hugo; Roig, Arturo (comps.), El pensamiento alternativo en la Argentina II, Buenos Aires, Biblos.

Preciado, Beatriz (2008), Testo yonqui, Madrid, Espasa.

Rascovsky Arnaldo; Schlossberg, Teodoro; Ferrari Hardoy, Gregorio; Olariaga, Tomás (1940), "Cuadros de desequilibrio entre maduración, crecimiento y sublimación en niños de edades similares", Archivos Argentinos de Pediatría, XI (14), pp. 642-654.

Rascovsky, Arnaldo; Pichon Riviere, Enrique; Salzman, Jaime (1940), "Elementos constitutivos del síndrome adiposo genital prepuberal en el varón." En Archivos Argentinos de Pe- diatría, XI (14), pp. 391-400

Rascovsky, Arnaldo; Salzman, Jaime (1940), “Estudio de los factores ambientales en el síndrome adiposo-genital en el varón", Archivos Argentinos de Pediatría, XI (14), pp. 527-537.

Rascovsky, Arnaldo; Salzman, Jaime (1941), Estudio de los factores ambientales en el síndrome adiposogenital del varón. (3a- comunicación). Archivos Argentinos de Pediatría, XV (16), pp. 342-356.

Rascovsky, Arnaldo; Schlossberg, Teodoro; Ferrari Hardoy, Gregorio (1940), "Síndrome de virilización suprarrenal en niñas", Archivos Argentinos de Pediatría, XI (14), pp. 377-398.

Rustoyburu, Cecilia (2012a), "Infancia, hormonas y género. Un análisis histórico de los discursos de la biotipología en Argentina en los años de 1930", Sexualidades, Salud y Sociedad-Revista Latinoamericana, 12, pp. 9-36.

Rustoyburu, Cecilia (2012b), Infancia, maternidad y paternidad en los discursos de la Nueva Pediatría (Buenos Aires, $1940-$ 1976). Tesis de doctorado en Ciencias Sociales, Buenos Aires, Facultad de Ciencias Sociales - Universidad de Buenos Aires.

Schencman, Pablo (2010), “¿Génesis de un problema sanitario? Representaciones de la biomedicina en torno de la obesidad en Viva Cien Años 1934-1945", Ëa Journal, vol 2 (2). [en línea] disponible en: http://www.ea-journal.com/art2.2/ Genesis-de-un-problema-sanitario-Representacionesde-la-biomedicina-en-torno-a-la-obesidad-en-Viva-CienAnos-1934-1945.pdf (Consultado el 18/05/2015)

Schere, Samuel (1938), "Algunas consideraciones sobre el tratamiento de la obesidad infantil", Archivos Argentinos de Pediatría, vol IX, 42-47.

Terman, Lewis y Miles, Catherine (1936), Sex and personality: Studies in masculinity and femininity, New York, McGraw-Hill.

$V^{\circ}$ Congreso Nacional de Medicina, Rosario (1934), Resumen de los trabajos presentados y discusiones correspondientes. Dr. Benito Soria (de Córdoba). Anomalías constitucionales del lactante y regímenes alimentarios", Archivos Argentinos de Pediatría, V (3), pp. 681-686.

Vezzetti, Hugo (1996), Aventuras de Freud en el país de los argentinos, Buenos Aires, Paidós.

Vigarello, Georges (1995), Lo sano y lo malsano, Montevideo, Trilce. 